\title{
Fístula Dentária Infraorbitária em Cão
}

\author{
Infraorbital Dental Fistula in Dog
}

\author{
Rayzza Rodrigues Perin*a; Natália Yoshioka De Vidisa; Munir Barriento de Azambuja; \\ Henrique Jorge Vieira Antunes Juniora; Jaqueline Anes de Souza ${ }^{a}$
}

\begin{abstract}
a Universidade Anhanguera Uniderp, Programa de Aprimoramento em Clínica Médica e Cirurgia de Pequenos Animais. MS, Brasil. *E-mail: rayzzaperin@gmail.com
\end{abstract}

\begin{abstract}
Resumo
A fístula infraorbitária é uma afecção comum em cães que acomete, geralmente, o quarto dente pré-molar superior, o único que possui três raízes, também denominado popularmente como "dente carniceiro", em função de suas funções de auxílio na caça e trituração de alimentos sólidos. As causas dessa enfermidade incluem traumas, fraturas de coroa, doenças periodontais, neoplasias, entre outras. Tais afecções geram infecção bacteriana no ápice alveolar da raiz dentária, juntamente com inflamação intensa, levando à osteólise da cavidade nasal ao seio maxilar, gerando assim um abcesso periapical, infraorbitário, que é observado nos animais acometidos. O diagnóstico ocorre, principalmente, por meio de avaliação da cavidade oral do animal sedado e de radiografia intraoral identificando áreas de radioluscência em torno do ápice da raiz acometida, evidenciando assim a osteólise e infecção bacteriana. A exodontia nem sempre é o tratamento indicado, pelo menos inicialmente. O caso relatado neste artigo é de uma paciente canina adulta diagnosticada com fístula infraorbitária, a qual passou por tratamento conservador e, apresentando recidiva, foi encaminhada para exodontia, sendo considerado bom prognóstico do quadro clínico no pós-cirúrgico e recuperação total após tratamento. Este trabalho tem como objetivo discorrer sobre essa afecção e elucidar, por meio de revisões bibliográficas, sobre as indicações de tratamento conservador, endodontia ou exodontia, facilitando assim a abordagem clínica diante dos casos.
\end{abstract}

Palavras-chave: Abscesso Periapical. Canino. Exodontia.

\begin{abstract}
Infraorbital fistula is a common condition in dogs that usually affects the fourth upper premolar tooth, the only one with three roots, also popularly referred to as the "butcher's tooth", because of its functions in hunting and grinding solid food. The causes of this disease include trauma, crown fractures, periodontal diseases, neoplasms, among others. Such conditions generate bacterial infection in the alveolar apex of the tooth root, together with intense inflammation, leading to osteolysis of the nasal cavity to the maxillary sinus, thus generating a periapical, infraorbital abscess, which is observed in the affected animals. The diagnosis is mainly made through the evaluation of the oral cavity of the sedated animal and intraoral radiography identifying areas of radiolucency around the apex of the affected root, thus showing osteolysis and bacterial infection. Extraction is not always the treatment indicated, at least initially. The case reported in this article is from an adult canine patient diagnosed with infraorbital fistula, who underwent conservative treatment and, with relapse, was referred for extraction, being considered a good prognosis of the postoperative clinical condition and full recovery after treatment. This paper aims to discuss this condition and to elucidate, through bibliographic reviews, about the indications of conservative treatment, endodontics or extraction, thus facilitating the clinical approach to the cases.
\end{abstract}

Keywords: Periapical Abscess. Canine. Extraction.

\section{Introdução}

A fístula dentária infraorbitária, também conhecida como “fístula do carniceiro" é uma lesão osteolítica entre o ápice do alvéolo e a cavidade nasal ou seio maxilar (DIAS, 2013; BONI, et al., 2016). Pode levar à formação de abscesso na face do paciente. É uma afecção comum em cães e que acomete, geralmente, o dente quarto pré-molar superior $\left(4^{\circ}\right.$ PMS). Isso ocorre em função de sua grande importância no processo mastigatório de alimentos sólidos, auxiliar na caça e autodefesa contra predadores. Portanto, em função de sua ampla utilização se torna mais predisposto a enfermidades (PIGNONE, 2009; RIBEIRO et al., 2015).

Entre as principais causas desta doença estão: periodontites, neoplasias, lesões periapicais, iatrogênicas ou traumas dentários (BONI et al., 2016; DIAS, 2013). Mesmo que um trauma dentário não gere fratura do tecido duro do dente (concussão sem fratura), pode causar hemorragia na polpa e levar à pulpite estéril, sendo que bactérias são atraídas ao local inflamado por anacorese. Essa pulpite pode evoluir para necrose pulpar e consequente fístula infraorbitária, se o dente afetado for o $4^{\circ}$ PMS (DIAS, 2011)

$\mathrm{O}$ dente quarto pré-molar superior, popularmente conhecido como "dente carniceiro", é o maior dente maxilar permanente dos carnívoros. É o único que possui três raízes distintas (mesiovestibular, mesiopalatina e raiz distal). Nos cães, as raízes estão inseridas nos alvéolos do osso maxilar, próximas à região infraorbitária (DIAS, 2013; PIGNONE, 2009).

Os sinais clínicos geralmente observados em cães incluem: aumento de volume gerando deformidade facial; fistulação 
cutânea com secreção piosanguinolenta; sensibilidade à percussão dentária e maxilar. $\mathrm{O}$ incômodo pode levar o animal a friccionar o focinho no chão ou com as patas. Podem ocorrer apatia; hiporexia; hipertermia; periodontite; halitose; sialorréia; hiperemia; retração gengival; gengivite; exposição de furca dentária e mobilidade dentária (DIAS et al., 2011; PIGNONE, 2009).

Além da anamnese, a inspeção oral com animal sob anestesia geral é muito importante para o diagnóstico de fístula infraorbitária (BONI et al., 2016). O exame fundamental para identificação das raízes dentárias acometidas é a radiografia intraoral, que evidencia as áreas radioluscentes ao redor do ápice da raiz afetada, que é causada pela osteólise e resposta inflamatória do organismo às bactérias e seus produtos (DIAS, 2011).

O tratamento desta afecção pode ser conservador, incluindo antibioticoterapia, anti-inflamatórios e tratamento endodôntico (tratamento de canal). Nos casos em que esse tipo de tratamento endodôntico não possa ser realizado, é indicada exodontia. O prognóstico é favorável nos casos em que a escolha do tratamento é adequada (BONI et al., 2016).

\section{Desenvolvimento}

\subsection{Relato do caso}

Foi atendida na Clínica Veterinária da Uniderp Agrárias (Universidade para Desenvolvimento do Estado e do Pantanal), no dia 03/05/2019, Nicole, um animal da espécie canina, sem raça definida (SRD), fêmea, com seis anos de idade, pesando $7,2 \mathrm{~kg}$, castrada. $\mathrm{O}$ animal apresentava aumento de volume e fístula com secreção purulenta abaixo do olho esquerdo. Observou-se, periodontite com provável acometimento do quarto pré-molar superior e espirros esporádicos. No exame físico não foi identificada alteração de parâmetros (temperatura, frequência cardíaca, frequência respiratória, coloração das mucosas, tempo de preenchimento capilar, palpação abdominal, palpação de linfonodos, hidratação). Suspeitou-se de fístula infraorbitária decorrente de lesão no quarto pré-molar superior esquerdo. Em novembro de 2017, ela já havia passado por antibioticoterapia com amoxicilina e clavulanato durante 10 dias em função dos mesmos sinais clínicos, o que caracteriza, portanto, uma recidiva. A terapia instituída desta vez foi com clindamicina (dose de $5 \mathrm{mg} / \mathrm{kg}$, bid*, via oral), até que fossem lançados os laudos dos exames complementares solicitados: radiografia intraoral, hemograma e perfil bioquímico. O resultado do hemograma revelou 9,4g/ dl de hiperproteinemia (referência: $5,5-8 \mathrm{~g} / \mathrm{dl}$ ). Os demais parâmetros avaliados no eritrograma, leucograma e perfil bioquímico (ALT, FA, creatinina e uréia) foram normais. No exame radiográfico intraoral foi observada lise periapical e área de radioluscência ao redor da raiz mais caudal do quarto pré-molar superior esquerdo causada pela osteólise, inflamação, bactérias e seus produtos (Figura 3). Diante da confirmação da fístula infraorbitária e identificação do dente e raízes acometidas, o animal foi encaminhado para exodontia de quarto pré-molar superior esquerdo.

Figura 1 - Radiografia intraoral de cão, SRD, fêmea, 7 anos de idade, com destaque em área radioluscente periapical em $4^{\circ} \mathrm{PMS}$, sugestivo de fístula infraorbitária

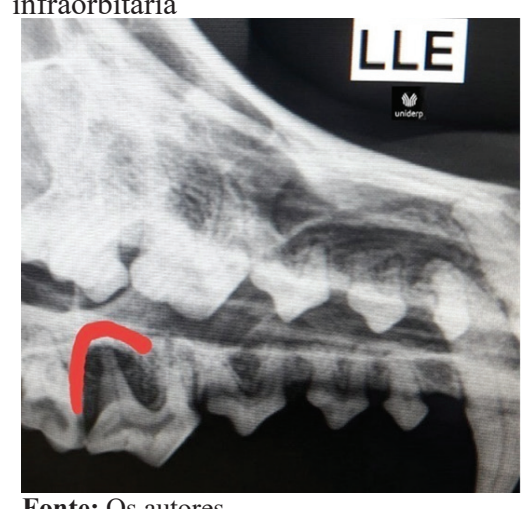

Fonte: Os autores.

A paciente recebeu acepromazina $(0,06 \mathrm{mg} / \mathrm{kg})$, e morfina $(0,5 \mathrm{mg} / \mathrm{kg})$, como medicações pré-anestésicas por via intramuscular, indução com tiletamina e zolazepam $(0,11 \mathrm{ml} /$ $\mathrm{kg}$ ) por via endovenosa, e manutenção com isoflurano por inalação.

A exodontia foi iniciada com o descolamento da gengiva (sindesmotomia) para o rompimento das fibras gengivais e, posteriormente, realizada a odontossecção e luxação dos fragmentos dentários. Estes foram removidos com auxílio de fórceps odontológico prevenindo lesões adjacentes. Foi realizada curetagem dos alvéolos dentários e sutura das mucosas orais com fio absorvível de ácido poliglicólico, sendo realizados pontos simples separados (DIAS, 2013; RIBEIRO et al., 2015). A ferida cutânea periocular foi amplamente tricotomizada, debridada e higienizada com solução fisiológica (Figura 2).

Figura 2 - Passos da exodontia, 1 - sindesmotomia; 2 e 3 - odontossecção; 4 - luxação dos ligamentos e remoção dos fragmentos dentários; 5 - Curetagem dos alvéolos; 6 - Sutura simples separada

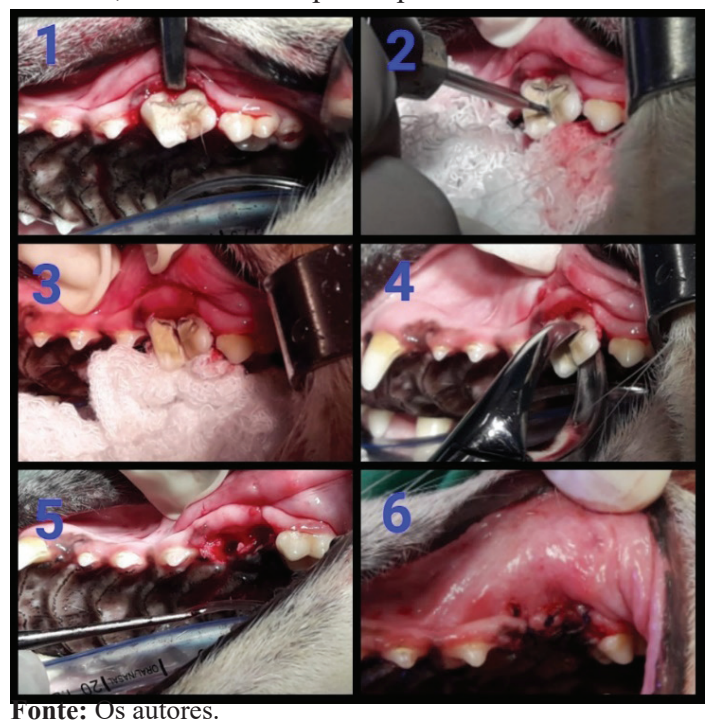


A prescrição pós-operatória do animal incluiu dipirona (25mg/kg, bid*), meloxicam $(0,1 \mathrm{mg} / \mathrm{kg}$, sid*, endovenoso), clindamicina $(5 \mathrm{mg} / \mathrm{kg}$, bid*, via oral $)$, ringer lactato $(250 \mathrm{ml}$, sid*, endovenoso) e spray oral tópico à base de digluconato de clorexidina à cada oito horas. Foi receitado após alta médica: clindamicina $(5 \mathrm{mg} / \mathrm{kg}$, bid*, 10 dias, via oral), meloxicam $\left(0,1 \mathrm{mg} / \mathrm{kg}, \mathrm{sid}^{*}, 10\right.$ dias, via oral $)$, spray oral tópico à base de digluconato de clorexidina a cada oito horas por 10 dias, uso de colar elizabetano e alimentação pastosa (BONI et al., 2016). O animal apresentou recuperação total após tratamento conforme pode ser observado na Figura 3.

*bid: (bis in die) $=$ duas vezes ao dia (a cada 12horas)

*sid: (semel in die) = uma vez ao dia (a cada 24horas)

Figura 3 - Completa cicatrização de lesão infraorbitária no olho esquerdo do cão, SRD, fêmea, 7 anos de idade, 15 dias após exodontia (indicado pela seta vermelha)

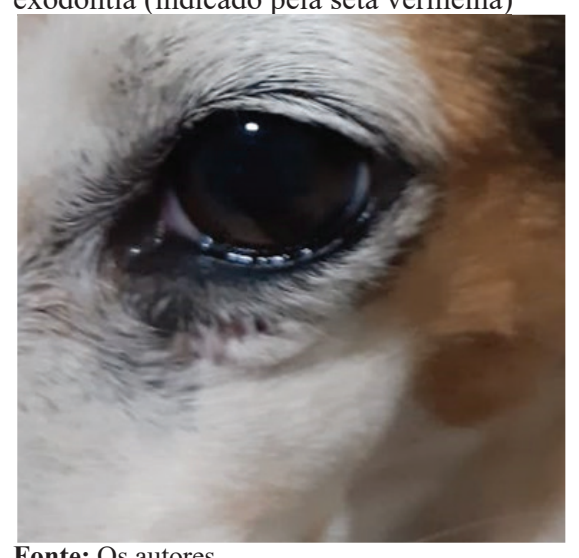

Fonte: Os autores.

Esta infecção, muitas vezes, pode ser tratada por longos períodos somente com a administração de antibióticos, não removendo o agente desencadeante, como no caso da paciente em questão que já havia passado por antibioticoterapia como tratamento de periodontite. No entanto, tal tratamento não foi efetivo, o que gerou recidiva pelo fato de não ter sido removido totalmente agente causador (BONI et al., 2016).

Apesar de existirem tratamentos e cirurgias periodontais que visam manutenção do quarto dente pré-molar superior, é necessário acompanhamento clínico e radiográfico com anestesia do paciente, o que pode ser oneroso ao proprietário. Entretanto, a exodontia é bastante realizada nestes casos perante o custo e por proporcionar resolução imediata e maior chance de sucesso (BONI et al., 2016). Dessa maneira, optouse por esta técnica para o tratamento da paciente deste relato. A decisão foi acertada uma vez que o animal se recuperou completamente.

\section{Conclusão}

Nem sempre a terapia endodôntica conservadora é a melhor escolha para tratamento de fístula infraorbitária canina. A exodontia do dente acometido foi eficaz na correção da fístula infraorbitária do caso em questão, diferente do resultado da terapia conservadora que gerou recidiva por não remover totalmente o agente desencadeante.

\section{Referências}

BONI, C.P. et al. Estudo retrospectivo de fístulas infraorbitárias em cães e gatos. Rev. Ed. Cont. Med. Vet. Zoot., v.14, n.2, p.54$55,2016$.

DIAS, F.G.G. et al. Fístula infraorbitária em cão: relato de caso. Rev. Cient. Elet. Med. Vet., v.9, n.16, p.1-13, 2011.

DIAS, F.G.G. et al. Fístula infraorbitária na espécie canina. Enc. Biosfera C. Cient. C., v.9, p.1453-1465, 2013.

PIGNONE, V. Utilização de bloqueio anestésico para exodontia do dente carniceiro em cão. Rev. Port. Cienc. Vet., v.104, n.569572, p.19-24, 2009.

RIBEIRO, I.M.M. et al. Fístula infraorbitária em cadela: Relato de caso. PUBVET, v.9, p.158-194. 2015.

ROZA, M.R. Princípios de odontologia veterinária. Brasília: Do Autor, 2012. 